\title{
El nihilismo como filosofía de nuestro tiempo
}

\section{Herbert Frey}

\begin{abstract}
Acerca de la génesis del nihilista. Sólo tardíamente solemos encontrar el valor de reconocer lo que en el fondo ya sabiamos. Apenas hace poco he admitido ante mi mismo que desde siempre he sido un nihilista radical. La energia y el radicalismo con los que procedi como nihilista me habian cegado ante este hecho fundamental. Cuando vamos en pos de un objetivo pareciera imposible que la "falta de rumbo en sí" sea la base de nuestra fe.

El cristianismo le administro veneno a Eros; esto no le causó la muerte pero hizo que se convirtiera en vicio.
\end{abstract}

Nietzsche

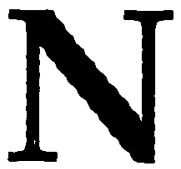

\section{ietzsche y la posmodernidad}

Si hemos de encontrarle un sentido al discurso de la posmodernidad accrca del fin de la modernidad, no podrá ser otro que el de señalar que la interpretación del mundo durante la modernidad siempre tuvo como fundamento la metafisica cristiana, y que la razón moderna fue en todo momento un producto de la secularización del concepto cristiano de Dios. El punto de partida común de todos los pensadores posmodemos es, en cambio, la muerte de la metafisica, de esa certeza de un mundo sobrenatural, de un valor supremo, legitimador del mundo, como lo expresara tan gráficamente Jean-François Lyotard en su libro La condición posmoderna. Con dicha obra, Lyotard trata de damos su punto de vista acerca de la situa. ción espiritual de nuestro tiempo, que refleja una condición de la filosofía de nuestros días. Su posición es la de quien ya no considera suya la tradición de la metafísica; es, por así decir, la posición de quien observa desde afuera el edificio terminado de la metafísica, sin considerarse ya habitante del mismo. La tarea planteada consistía en "estudiar nuestra civilización con los ojos del etnólogo", es decir, ubicarse fuera de ella y observarla con la mirada distanciada de la no pertenencia. Sólo así resultaba posible enfocar la mons- 
truosidad del proceso de la occidentalidad que hasta ahora se había aceptado como algo natural. Seguramente los pensadores posmodernos más destacados de la actualidad no titubearían en suscribir la tesis de que la razón moderna no fue otra cosa que teología disfrazada que ha logrado someter a Occidente de manera autoritaria, sin que éste se percatara de ello.

Pero si esta es una posición comúnmente reconocida, en la que coinciden los fundadores de la posmodernidad, no debe extrañarnos a quien le corresponde el verdadero mérito de ser el autor intelectual de esta tendencia: nadie menos que Friedrich Nietzsche.

Quien comparte con Nietzsche el rechazo radical del cristianismo, ocupa, aún hoy en día, una posición solitaria, ya que se enfrenta a una tradición occidental que ha condenado a la hoguera a todo aquello que pudiera poner en tela de juicio su monopolio. Tratándose de cuestiones religiosas, conviene tomar con la debida desconfianza todas esas declaraciones de adhesión demasiado locuaces en favor de Nietzsche. Aún en nuestros días -al menos por ahora- no se ganan elecciones con Nietzsche como abanderado. El gélido aire de las alturas resulta difícil de soportar para el individuo solo, y ni que hablar de aquél que lleva mujer y bebé en sus brazos. Ante múltiples catástrofes, el Occidente, en vías de unificación, se presenta bien arregladito y posmoderno; el catolicismo o también el protestantismo han dejado de ser candentes. La actitud es distanciada: se le perdonan a un papa fanatizado sus invectivas en materia de moral sexual, haciendo énfasis en la autonomía de la intimidad, pero no sin llevarle la corriente a un cristianismo castrado que resulta tan tranquilizante para las masas como para uno mismo. La posmoder. nidad, al menos en sus epígonos, ha hecho las paces con las ideas religiosas de Occidente; un cristianismo bien temperado cuadra perfectamente con los hogares pequeñoburgueses bien abrigados y mal ventilados. Con una mentalidad blandengue del "todo está permitido", ajeno ya al pathos de Dostoievsky, el posmodernismo atomizado en sus derivados, está a punto de darle carta de ciudadanía, en Italia, a un partido fascista que se desliza sobre patitas de terciopelo, escudándose tras el hecho de que sólo profiere vivas al Duce en domingos y días festivos absteniéndose, por lo demás, de poner obstáculos a los engranajes del capitalismo.

La radicalidad de Nietzsche, el amor por esa radicalidad, si se toma en serio, sigue generando hoy en día esa soledad que en aspectos sustanciales raya en locura. Porque aun cuando el nihilismo de Nietzsche es, sin lugar a dudas, la filosofia de nuestro tiempo, de la cual no hay vuelta atrás, ocurre con ella lo mismo que con la teoría de la relatividad de Einstein, que, si bien se reconoce como la teoría física más avanzada, tiene para la vida del individuo la misma importancia que el nihilismo de Nietzsche, es decir, la de la inexistencia. Desde el punto de vista de las ideas, los sectores políticos y 
económicos se dan el lujo de no estar precisamente a la altura de nuestro tiempo, compartiendo el nivel intelectual con las cadenas internacionales de televisión, para las cuales la filosofía actual, o más bien, toda la filosofia, carece de atractivo para el público. A éste mejor se le asegura un tranquilo sueño de fin de semana con algún gratificante sermón o se le complace con los mensajes apasionados y pletóricos de autoincriminaciones de predicadores protestantes fundamentalistas estadounidenses.

Pero las fórmulas mágicas de conjuro tienen una cosa en común con el opio: el que su efecto tranquilizante es efimero, requiriendo de dosis cada vez más altas. Es cada vez mayor el número de individuos pensantes que considera imposible el retorno a un mundo aparentemente sano en Occidente, aun cuando tal parecer descansa en la mayoría de los casos más bien en una vaga sensación y no en una certeza racionalmente fundada. Pero el hecho de que los conceptos de racionalidad que se han desarrollado a lo largo de más de dos mil años hasta imponer su dominio y prevalencia se encuentran ahora en un callejón sin salida, manifestado en crisis de sentido y pérdida del telos, es algo que comienza a inquietar cada vez más la conciencia de nuestro coetáneos.

\section{Discurso sobre la "Muerte de Dios"}

Con su característico estilo poético-sensual, Nietzsche formuló esta crisis de sentido de Occidente por vez primera en la parte CXXV del Libro Tercero de La Gaya Ciencia, que trata de "el Loco". La búsqueda de la integridad desaparecida de Occidente aparece aquí como la búsqueda del Dios perdido, cuya acción persistente como espíritu le había proporcionado la continuidad a Occidente.

"¿Dónde está Dios?" exclamó, Os lo diré: le hemos dado muerte; vosotros y yo, itodos somos sus asesinos! Pero ¿cómo hemos podi. do hacerlo? ¿Cómo pudimos vaciar el mar? ¿Quién nos dio la esponja para borrar el horizonte? ¿Qué hemos hecho al desprender la tierra de la cadena de su sol? ¿Hacia dónde la conducen ahora sus movimientos y a dónde nos llevan los nuestros? ¿Acaso lejos de todos los soles? ¿Es que no caemos sin cesar? ¿Caemos hacia adelante, hacia atrás, hacia algún lado, en todas direcciones? ¿Aún existe un arriba y un abajo! ¿No andamos errando por una nada infinita? ¿No nos persigue el hálito del espacio vacío? ¿No está haciendo más frío? ¿No persiste la noche, una noche cada vez más cerrada? ¿No tenemos que encender los faroles antes del mediodía? ¿Aún no escuchamos el rumor de los sepultureros que entierran a Dios? ¿No 
percibimos aún el olor de la descomposición divina? ¡También los dioses se descomponen! ¡Dios ha muerto! ¡Dios permanece muer-. to! ¡Y nosotros le dimos muerte!?

Este fragmento de La Gaya Ciencia expresa un diagnóstico sobre Occidente. La muerte de Dios es un acontecimiento que marca una censura en la historia actual. En efecto, la culminación a la vez que el fin de la espiritualidad occidental se revelan aquí como un ocaso de los dioses, y no como una autoiluminación. Es el diagnóstico del fin de la metafísica, cuya personificación general esta cifrada en Dios. La muerte de Dios no sólo provocó el derrumbamiento del sistema global de interpretación, consolación e invención de sentido del espíritu occidental, sino también la pérdida de la certeza de un mundo sobrenatural que proporcionaba respuestas a las preguntas del hombre sobre el sentido de la existencia. Pues en el mundo occidental la palabra "metafísica" en un principio no significaba otra cosa que eso: la certeza de lo sobrenatural. La muerte de la metafísica significaba para Nietzsche el fin de la filosofía occidental en su manifestación platónica y cristiana, y que sus intentos de interpretación y creación de sentido se habían agotado. ${ }^{2}$ Lo que hasta entonces le había parecido a la humanidad como valor supremo de la existencia, acababa por revelarse como nulo. En este sentido, Nietzsche hablaba de la desvalorización de los valores, aludiendo al proceso en que ve encaminado a Occidente con el romanticismo y su pesimismo.

"¿Qué significa nihilismo? Significa que los máximos valores pierden su valor. Falta una meta. Falta la respuesta ante la pregunta del "¿para qué?".

Este es, en resumen, el diagnóstico de Nietzsche para describir la situación después de la muerte de Dios, que encontramos en su legado de los años ochentas. El causante de la muerte de Dios no es el Loco de La Gaya Ciencia; es la época misma, con los cambios que le son inherentes, la que se opone a la existencia de Dios. ¿Qué quiere decir "hemos dado muerte a Dios" y "cómo hemos podido hacerlo"? Quiere decir que el racionalismo, el uso de las fuerzas para dominar la naturaleza y liberarse de autoridad y tutelaje ajenos son incompatibles con la existencia de un Ser Supremo. Estas conclusiones, hechas con un resabio de melancolía, provienen de un Nietzsche producto de una Ilustración que se ha vuelto transparente para sí misma, un Nietzsche que se refiere a sus escritos como una "escuela de sospechas". No en vano menciona el Loco el desprendimiento copernicano del Sol de la Tierra o el descubrimiento - hecho a principios de la era moderna- de la infini-

${ }^{1}$ Friedrich Nietzsche, Werke in drei Bänden, t. Il. Munich, Schlechta, 1966, p. 127.

${ }^{2}$ Cf. M. Frank, Was ist Neostrukturalismus? Francfort, 1983. 
dad del Universo, donde ya no hay un arriba ni un abajo, $y$, por ende no se cuenta con puntos de orientación para una existencia que ha perdido su base de sustentación.

En 1886, Nietzsche escribe:

El más importante de los acontecimientos recientes, "la muerte de Dios" y el hecho de que la fe en el Dios cristiano haya perdido su credibilidad, empieza a proyectar sus primeras sombras sobre Europa. ${ }^{3}$

El esclarecimiento de las condiciones teológicas de nuestro pensamiento condujo a la destrucción del mundo sobrenatural en todas sus manifestaciones: como valor supremo, como autor divino del mundo, como substancia absoluta, como nexo entre el sentido y la comunicación y, finalmente, como sujeto creador y ejecutor de la técnica y ciencia modernas.

También podría formularse de otra manera: el examen racionalista de la idea de Dios y de las teorías sobrenaturales del pensamiento occidental no levó a ningún resultado: ni Dios ni los valores trascendentes poseen significado alguno. Es precisamente en ese momento que "la más temible de las visitas", el nihilismo europeo, toca a la puerta. "Pero el origen de este nihilismo, que representa meramente el proceso de concientización de un largo extravio de Occidente, yace en la constitución misma de Occidente. La verdadera originalidad de Nietzsche reside en haberle dado ese giro a la historia, al situar los primeros indicios del nihilismo (la sospecha del nihilismo) en los comienzos de la historia occidental; "el nihilismo radica en una inter. pretación muy específica, esto es, en la interpretación moral-cristiana"

Es asi como esa misma moral, que se vuelve contra su Dios, es la causa de la ruina del cristianismo. Es la misma veracidad (altamente desarrollada en el contexto cristiano) la que se asquea ante la falsedad y mendacidad de la interpretación cristiana del mundo y de la historia. Se produce una inversión: "Dios es la Verdad" se convierte en "Todo es falso". Ese es el precio que se tiene que pagar por haber mantenido la creencia milenaria en el Dios judeo-cristiano. En este punto, Nietzsche continúa diciendo en su legado de los años ochentas:

Lo decisivo es tener una actitud escéptica ante la moral. El derrumbamiento de la interpretación moral del mundo, que ha perdido su

\footnotetext{
${ }^{3}$ F. Nietzsche, op. cit., t. II, p. 205.

${ }^{\prime} \mathrm{F}$. Nietzsche, op. cit., t. III, p. 881.

'Idem.
} 
vigencia tras haber intentado refugiarse en lo ultraterrenal, termina en el nihilismo. "Nada tiene sentido". (El carácter irrealizable de una interpretación del mundo, en la que se ha invertido un esfuerzo ingente, suscita la sospecha de que toda interpretación del mundo adolezca de falsedad). ${ }^{6}$

Con la muerte definitiva de Dios no sólo llegó a su fin una época (la de la Edad Media y de la superstición), sino también marcó el final de la metafi. sica en sí y en todas sus variantes, es decir, todos aquellos aspectos del ser en cuyo contexto se habían situado las estructuras de sentido de Occidente. La destrucción de este marco de referencia provocó una falta de orientación muy diferente a aquélla propiciada por la naciente Edad Media cristiana durante la época de decadencia de la Antigüedad, o la que la desaparición de la Edad Media suscitó en los científicos de la Era Moderna. En ninguna de estas épocas se produjo la destrucciớn radical de la estructura que daba sentido a Occidente (es decir, su comprensión global del mundo), sino que, en ambos casos, simplemente una interpretación fue sustituida por otra -digamos, generalizando, que "Dios" se suplantó por "razón"- a la vez que quedarón intactas las tendencias de evolución y las metas vigentes hasta ese momento. Pero en el fondo, también la razón seguía concibiéndose en términos teológicos, como lo comprueba elocuentemente todo el sistema estructural de Hegel.

Con la llegada del nihilismo, en cambio, se desmanteló también la sabi. duría suprema como último bastión de la confianza en el mundo, condenándosenos a "errar por un vacío sin fin"

Con la muerte de la metafísica (o sea; de la certeza de un mundo sobrenatural) se creó una situación que dio inicio al fin de la Modernidad -diagnosticado por Nietzsche y proclamado por los teóricos de la posmodernidad como punto de partida de su pensamiento.

Sin embargo, Nietzsche no concèbía el "errar por un vacío infinito" como el punto final de la historia, sino como un nuevo comienzo, como una vuelta hacia valores basados en la vida y en el eros de la vida; valores que durante la historia de Occidente fueron condenados y desacreditados en aras de un más allá superior. Aunque, ciertamente, todavía había que pagar el precio por haber creído en un "mundo verdadero", puesto que una falta de orientación temporal constituía la etapa de transición que permitiría alcanzar nuevos horizontes.

${ }^{6}$ Idem. 
Llegará una época, dijo Nietzsche, en que tendremos que pagar el precio por haber sido cristianos durante dos milenios: perderemos el centro de gravedad que nos permitía vivir, y durante un tiempo no sabremos qué hacer. Nos precipitaremos en dirección opuesta a nuestros valores con la misma energía que ocasionó tamaña sobrevaloración del hombre en el hombre.

No obstante, el derrumbamiento de los valores cristianos no sólo condujo a la catástrofe de la desorientación, sino también a su contrario. En este sentido, cabe recordar las exultantes palabras de Gottfried Benn, quien en un discurso pronunciado en 1931 con ocasión del sesenta aniversario de Heinrich Mann, describió al nihilismo como una sensación de felicidad. Para nosotros, el nihilismo es algo demasiado presente y familiar como para poder celebrar la liberación de los viejos valores tan efusivamente como todavía lo hizo Gottfried Benn.

\section{E1 cristianismo como creador del nihilismo}

Occidente vivió demasiado tiempo en el engaño de su cosmovisión que había sacrificado todo lo establecido, así como el simple placer del momento, en aras de la eternidad que prometía el paraíso. Nietzsche fue el primero en señalar el extravio de la tradición judeo-cristiana y en derivar de ahí la necesidad de una inversión de todos los valores cristianos. El nihilismo es un concepto que no se acuñaría sino hasta el siglo XIX, un siglo que vería surgir la conciencia de la insostenibilidad de la religión cristiana. El nihilismo repre. senta una reacción contra los valores superiores, cuya existencia y validez negaba; ya no era cuestión de desvalorizar la vida en nombre de estos valores, sino todo lo contrario: desvalorizar los valores en sí. Pero este concepto del nihilismo señalaba tan sólo una etapa final, la de la destrucción de los valores que habían tiranizado y subyugado la verdadera existencia. Según Nietzsche, el origen real del nihilismo no radicaba en esta última fase de destrucción, sino en los albores de una religión que había negado la existencia del mundo real y trasladado la verdadera realización de la vida a un más allá, para el cual el más acá sólo servía de estado intermedio. La gran catástrofe de la historia occidental era resultado de la invención del dios judio Yahvé, quien encarnaba la concentración máxima del poder en un sólo dios situado en el más allá. Porque este acto no sólo privó al mundo de su sentido inmanente, sino que además estableció la Teoría de los Dos Mundos, la cual desvalorizaba la naturaleza y el cosmos y degradaba los valores naturales. Con la invención de ese

'I Ibid., p. 665. 
dios único, la naturaleza quedó a merced de la intervención despiadada del hombre y se constituyeron los principios de una razón instrumentalista, que ha conducido a la incontrolable destrucción de la naturaleza en nuestros días. ${ }^{8}$ Según Max Weber, el dios del Medio Oriente era una fiel imagen del déspota asiático: un dios que no toleraba la presencia de otros dioses; un dios que, al no formar parte de la naturaleza, había convertido a ésta en objeto de explotación, rompiendo así el hechizo que le había conferido valor propio. Esta es esencialmente la razón por la cual, en El Anticristo, Nietzsche se refiere a los judíos como "al pueblo más funesto de la historia de la humanidad". No lo decía porque fuera antisemita, sino porque veía en el monoteísmo judeo-cristiano la causa de la perdición de Occidente.

Los judíos son el pueblo más peculiar de la historia, ya que, confrontados con el dilema de ser o no ser, decidieron ser a cualquier precio, con una determinación verdaderamente inquietante: ese precio implicó la alteración racial de toda la naturaleza, de toda naturalidad, de toda realidad y de todo el mundo interior no menos que del exterior. Repudiaron todas las condiciones bajo las cuales los pueblos habían podido vivir, o habían tenido derecho a vivir hasta entonces; crearon a partir de sí mismos un concepto antitético a las condiciones naturales -convirtieron, sucesiva e irremediablemente, la religión, el culto, la moral, la historia y la psicología en lo contrario de los valores naturales inherentes a su esencia.?

Para Nietzsche, el cristianismo simplemente continuó la tradición judaica; de ahí que su concepto de dios carezca de toda originalidad. Ambas cosmovisiones comparúan el odio a los valores naturales y a cualquier manifestación de afirmación pagana del mundo.

Para poder negar todo aquello que representara la evolución ascendente de la vida, la armonía plena, el poder, la belleza, la autoafirmación en la Tierra, el instinto genial del resentimiento tuvo que idear otro mundo, donde esa afirmación de la vida suponía la esencia de lo malo y reprobable. ${ }^{10}$

La originalidad de Nietzsche en la historia de la crítica religiosa occidental consiste precisamente en buscar los orígenes del nihilismo en la inven-

${ }^{8}$ H. Cox, La ciudad secular. Barcelona, 1968, pp. 43-46.

${ }^{9}$ F. Nietzsche, op. cit., t. II, p. 1184.

${ }^{10}$ Idem. 
ción del monoteísmo judeo-cristiano, convirtiendo así la historia de Occidente en la historia del nihilismo. Nietzsche no hace más que descubrir las fatales consecuencias de esa historia y, a partir de ahí, sacar sus propias conclusiones. El cosmos de los griegos habia estado poblado de dioses, en los cuales el hombre podía adorarse tanto a sí mismo como a su afirmación de la vida: el Hades existía, pero solamente como un lugar donde ya nada había que esperar. El cosmos griego desconocía la moral; era la suprema encarnación de un mundo afirmativo, que contenía por igual el placer y el dolor y que no podía someterse al veredicto de un más allá. La negación del mundo no provenía de los dioses, sino de aquel Dios único; El era el origen de la moral y de los dogmas, Él era el gran enemigo de la visión mítica del mundo. Al final de la historia, Nietzsche expresa en una sola frase todo el hastio ante el dogmático Dios del cristianismo: “ $i$ En casi dos milenios ni un solo nuevo dios!". ${ }^{11}$ Más adelante ilustra la desilusión ante la esterilidad de las antaño brillantes habilidades del hombre, exclamando: " $i Y$ cuántos dioses más podrian existir!" Ambas frases señalan una nueva situación limítrofe, cuya principal demanda reside en la necesidad de una "remitificación". ${ }^{12}$

Para Nietzsche, el verdadero enemigo no era la religión como tal, y mucho menos aun el mito, sino aquella cosmovisión judeo-cristiana que había creado el más allá y provocado así la desvalorización del más acá.

¡Dios degenerado en negación de la vida, en vez de ser su etema glorificación y afirmación! ¡Dios como encamación de la hostilidad contra la vida, contra la naturaleza y la voluntad de vivir! ¡Dios como fórmula de toda detracción del "más acá" y de toda mentira sobre el "más allá"! ¡En Dios, divinizada la nada y santificado el deseo por alcanzarla!"

Al separar lo divino de este mundo, el mundo realmente existente fue privado de su valor inmanente para convertirse en un mero estado intermedio, mientras que el sentido de la vida fue confinado a otro mundo, único lugar donde se realizarían los deseos y los sueños. El Dios único, verdadero y trascendente de las religiones monoteístas demandaba para sí mismo toda la atención de los hombres, prohibiéndoles aceptar lo que el mundo les ofrecía de placer y concupiscencia. Todo lo que ataba al hombre a la Tierra fue catalogado como vicio por el cristianismo. Entre todas las religiones monoteístas, Nietzsche consideraba al cristianismo como su enemigo por

\footnotetext{
"Ibid., p. 1178

${ }^{12}$ H. Blumenberg, Arbeit am Mythos. Francfort, 1979, p. 36.

${ }^{13}$ F. Nietzsche, op. cit., t. II, p. 1178.
} 
excelencia, puesto que representaba la interpretación dominante e incuestionada de Occidente, la cual se oponía a cualquier manifestación libre del espíritu y a cualquier relación erótica con el mundo. La profunda aversión del cristianismo hacia cualquier manifestación de placer se explica por el hecho de que el placer es absolutamente autosuficiente $y$ no reconoce ningún objetivo fuera de sí mismo, volviendo así superfluo el Reino de los Cielos.

"Si el peso de la vida se sitúa en el 'más allá' -o sea, en la nada-, en lugar de situarlo en la vida misma, ésta se ve despojada de todo peso". ${ }^{14}$

Esta cita de Nietzsche proviene de su tratado combativo El Anticristo -escrito en septiembre de 1888-, el cual representa uno de los ataques más contundentes contra el cristianismo y la Iglesia que jamás se hayan redacta. do en el siglo XIX. En este mismo escrito, Nietzsche expresa:

Aquí se desprecia el cuerpo y se repudia la higiene como una forma de la sensualidad $[. .$.$] Lo cristiano equivale a un cierto sentido$ de crueldad tanto para consigo mismo como para con los demás; supone un odio a los que piensan diferente y un deseo de persecución.

Cristiana es la hostilidad enconada al espíritu, al orgullo, a la valentía, a la libertad y al libertinaje del espíritu; cristiano es el odio a los sentidos, a los placeres sensuales, a la alegría en general. ${ }^{15}$

La condena final y el enjuiciamiento definitivo que Nietzsche hace del cristianismo en $E l$ Anticristo no recae únicamente en la religión cristiana, sino sobre todo en el sistema de valores de Occidente, puesto que nunca antes habían sido cuestionadas tan radicalmente las formas de vida y los conceptos de moral que imperaban en esa parte del mundo.

Quisiera escribir esta perpetua acusación al cristianismo en todas las paredes que encuentre [...] Llamo al cristianismo la gran maldición, la gran corrupción interna, el gran instinto de venganza; para el cual ningún medio es lo suficientemente alevoso, misterioso, subrepticio y mezquino; le llamo, en resumen, la eterna mácula de la humanidad. ${ }^{16}$

${ }^{14}$ Ibid., p. 1205.

${ }^{15}$ Ibid., p. 1181.

${ }^{16}$ Ibid., p. 1235. 


\section{La vuelta hacia el mundo: Dioniso contra el Crucificado}

En cierto modo, Nietzsche encarna al perfecto vengador de la aniquilación que sufrió la cosmovisión antigua bajo la interpretación cristiana del mundo, pues su programa es toda una rehabilitación del mundo griego antiguo, con su afirmación de la vida y del mundo.

Dioniso contra el Crucificado: he ahí la antítesis. Su diferencia no se basa en el martirio, sino en el sentido que a éste se le otorga. La vida misma, con su infinita fecundidad y su eterno retorno, es la causa de la tortura, de la ruina y de la voluntad de destruir. En el otro caso, el sufrimiento y la "inocencia del Crucificado" sirven como pretexto para contradecir a la vida, como fórmula de su condena. -Está claro: el problema yace en el sentido del sufrimiento, sea que se trate de un sentido cristiano o bien trágico. En el primer caso se pretende que nos conduzca a una existencia santificada; en el segundo, se considera que la existencia misma es lo suficientemente sagrada, como para justificar el más terrible sufrimiento. El hombre trágico es capaz de aceptar el peor de los tormentos: es lo bastante fuerte, pleno y divinizante para ello; el cristiano reniega aun de la mejor de las suertes sobre la Tierra: es lo bastante débil, pobre y desheredado para padecer la vida en todas sus formas. El dios crucificado es una maldición a la vida, una señal para liberarse de su presencia; -Dioniso despedazado es una promesa de vida: renace eternamente, $y$ de la destrucción retoma a la vida. ${ }^{17}$

El semidiós griego Dioniso, originario de Tracia, era para Nietzsche el símbolo de una cosmovisión diametralmente opuesta a la racionalidad occidental. Era el dios del vino, del éxtasis y de la vida orgiástica, en la cual están intimamente ligados el placer, la crueldad y la espontaneidad; es el dios del aquí y del ahora. Según la mitología griega, Dioniso nació de una mujer mortal, Sémele, hija del rey Cadmo de Tebas, que tuvo amoríos con Zeus, el dios padre de los griegos. De esta unión nació Dioniso, quien desde entonces sufriría la persecución de Hera, esposa de Zeus. El destino del pequeño semidiós transcurría bajo la protección de Zeus y el asedio de la venganza de Hera. Los viejos enemigos de Zeus lo despedazan, sólo para verlo renacer bajo el cuidado de su padre. Condenado a la locura por Hera, el dios, que mientras tanto había descubierto el vino y el éxtasis, vagaba por el mundo en compañia de una caterva salvaje de sátiros y ménades. Orgías y bacanales

${ }^{17}$ F. Nietzsche, op. cit., t. III, p. 773. 
escoltaban su camino, pero también la cultura del vino y del trigo. Extasis y asesinatos rituales - que no eran otra cosa que remedos del despedazamiento y resurgimiento del propio Dioniso- sembraban miedo y placer a donde quiera que iba este dios. La afirmación de lo terrenal y el gusto por la destruc. ción -inseparablemente unidos en la figura simbólica de Dioniso- constituyen atributos esenciales de la cosmovisión dionisíaca.

En pocas palabras: Dioniso es el dios que no tiene en alta estima el principio de individualidad y todo lo arrastra al éxtasis, que convierte a las "mujeres en hienas", rompe los límites entre los sexos $\mathrm{y}$, en general, manipula a su antojo los diferentes ámbitos de la existencia, ora arrastrándolos al torbellino de la identidad indiferenciada, ora separándolos al torbellino de la identidad indiferenciada, ora separándolos nuevamente para diferenciarlos en un sentido literal, como dios del progreso y de la evolución. Así representa ambos principios a la vez: tanto el de la unión como el de la separación. Y este doble don lo predispone para asumir el poder especial de convertirse en "dios de todos los dioses": la encarnación del mito politeísta, a la vez que su propia anulación. ${ }^{18}$

Dioniso, dios de la Ticrra, hace de su desmembramiento su más alto triunfo y encarna así, al mismo ticmpo, la tormentosa belleza que acompaña el dolor. Según Nietzsche, la afirmación de la Tierra y de Dioniso conlleva igualmente la afirmación de sus sufrimientos. Aceptarlo todo, tanto la máxima contradicción como el más profundo dolor, significa dominarlo todo.

Para Nietzsche, lo único verdadero es la Tierra seria y sufriente; ella es la única divinidad. Empédocles, ese mítico personaje de la Antigüedad, se precipitó al cráter del Etna para encontrar la verdad en las entrañas de la Tierra y, finalmente, unirse a ella. Nietzsche, en cambio, le recomienda al hombre precipitarse al cosmos para reencontrar su divinidad eterna y, así, convertirse él mismo en Dioniso.

El cristianismo creía combatir el nihilismo al imponerie al mundo sus objetivos, cuando en realidad daba evidencia de su propio carácter nihilista, al dotar a la vida de un sentido imaginario que le ocultaba al hombre su verdadera determinación.

En contraste con el dios incondicional y omnipotente del monoteísmo, Nietzsche veía esbozado en el politeísmo lo que se con-

${ }^{18}$ M. Frank, Der kommende Gott. Vorlesungen über die neue Mythologie. Francfort, 1982, p. 20. 
vertiría en el programa de su propia filosofia: recordar la libertad de pensamiento y el espíritu plural del hombre, "la facultad de crearse ojos nuevos y personales, cada vez más nuevos y más personales, de suerte que sólo para el hombre entre todos los animales no haya horizontes ni perspectivas eternas" ${ }^{19}$ en oposición a la servidumbre exclusiva ante una verdad rígida y dogmática que pretendía establecer normas y compromisos atemporales. ${ }^{20}$

La propuesta de Nietzsche para el mundo consiste en emanciparse de las ideas que nos fueron inculcadas y volver a lo que él considera la única certeza real: la Tierra, como la única verdad posible para el hombre; es a ella a quien el hombre le debe ser fiel, es en ella donde ha de vivir y buscar su salvación.

Nietzsche nos sugiere aceptar la inocencia del mundo tan pronto como seamos capaces de reconocer su carencia de objetivos, al igual que la incompetencia de nuestro juicio, puesto que a falta de intención no cabe el veredicto; en consecuencia, debemos sustituir nuestros juicios valorativos por un único y rotundo "si", una afirmación irrestricta y entusiasta de este mundo. ${ }^{21} \mathrm{El}$ mundo es divino porque no tiene finalidad ni fundamento; lo mismo sucede con el arte, por lo cual éste es la única manifestación capaz de representar adecuadamente al mundo con toda su carencia de objetivos. Para Nietzsche en realidad sí existe un dios, que es el mundo. Para poder participar de su divinidad basta con decir "si". La aceptación del mundo implica recrear el mundo y recrearse a sí mismo, a la vez que crear las leyes bajo cuyos auspicios habría de colmar la Tierra una nueva afirmación del mundo.

Mi nuevo camino al sí. Como hasta ahora, la he vivido y entendido, la filosofía también es la búsqueda voluntaria del lado abominable y perverso de la existencia [...] Una filosofía experimental, como yo la vivo, anticipa por sí misma, a modo de prueba, las posibilidades del principio nihilista, sin por ello permanecer en la negación, en el no, es decir, en la voluntad de decir "no". Antes bien desea alcanzar lo opuesto, o sea, llegar a la afirmación dionisíaca del mundo tal y como es, sin menoscabo, sin reserva y sin elección; desea el ciclo eterno de las mismas cosas, la misma lógica y falta de lógica del nudo. El máximo estado que un filósofo puede alcanzar, es

${ }^{19}$ F. Nietzsche, op. cit., t. II, p. 135.

${ }^{20}$ W. Lange, "Tod ist bei Göttern immer nur ein Vorteil. Zum Komplex des Mythos bei Nietzsche", en K. H. Bohrer, Mythos und Moderne. Francfort, 1983, p. 1218.

${ }^{21}$ A. Camus, Der Mensch in der Revolte. Reinbeck, 1969, p. 61. 
adoptar una actitud dionisíaca hacia la vida: mi fórmula para lograrlo es el amor fati. Para ello hemos de comprender que las partes hasta ahora negadas de la existencia no sólo son necesarias, sino deseables. ${ }^{22}$

Con la muerte de Dios, el hombre debe imponerle al mundo, que no conoce objetivo ni finalidad, sus propias perspectivas a manera de telos, y es el hombre quien comprende la historia como carente de determinación, como material que habrá de moldear según sus propias ideas. Así, Nietzsche le devuelve al hombre aquellas cualidades creativas que, en realidad, siempre había poseído sin tener conciencia de ellas.

Toda la belleza y majestad que prestamos a las cosas reales e imaginarias la reivindicaré como fruto y propiedad del hombre, como su más hermosa apología [...] Su mayor altruismo consistió hasta ahora en admirar y adorar, y saber ocultar el hecho de que era él quien había creado aquello que admiraba. ${ }^{23}$

Dado que el mundo es la única e imprescindible realidad del hombre, ese mundo no debe ser desvalorizado, sino reconocido con todo su carácter contradictorio.

"Un espíritu de tal modo liberado se sitúa en medio del cosmos con un fatalismo gozoso y confiado, convencido de que sólo lo particular es ruin y de que en el Todo se redimen y afirman todas las cosas; ya no niega nada". ${ }^{24}$

Nietzsche descarta la necesidad de preguntar por un sentido del mun. do, puesto que tal pregunta parte de una cosmovisión tradicional que había interpretado el mundo desde siempre como un fenómeno condicionado.

"El valor total del mundo es innegable; en consecuencia, el pesimismo filosófico forma parte de lo cómico". ${ }^{25}$

\section{El nihilismo como destino ineludible}

"Lo que relato es la historia de los próximos dos siglos. Describo lo que vendrá, porque no puede ser de otra manera: el advenimiento del nihilis$\mathrm{mo}^{\prime 2}{ }^{26}$

${ }^{22}$ F. Nietzsche, op. cit., t. III, p. 834.

${ }^{23}$ Ibid., p. 680.

${ }^{24}$ F. Nietzsche, op. cit., t. II, p. 1025.

${ }^{25}$ F. Nietzsche, op. cit., t. III, p. 685.

${ }^{26}$ Ibid., p. 634. 
El cristianismo le había deparado al mundo y a la historia un sentido artificial, cuya destrucción, en primera instancia, dejó un vacío que impidió el enlace directo con una afímación incuestionada del mundo. Situado durante dos mil años en el centro del cosmos y de la historia, el hombre había derivado su propio valor de la religión cristiana, asumiendo una interpretación del mundo que le garantizaba la posición clave no sólo en el planeta Tierra, sino en todo el universo. Retomar una cosmovisión como la de los griegos implicaba pérdida de sentido; se aniquilaba así la perspectiva central del hombre, quien trató de resistir, durante mucho tiempo, a esa destruc. ción.

Nietzsche nos habla de una "traba"; pero ¿una traba contra qué? Pues bien, una traba para no tomar conocimiento de la descentralización incontenible que experimenta el hombre; para resistirnos a aceptar la amarga realidad de que el mundo no fue hecho para el hombre, sino que éste mismo es sólo un producto fortuito, perfectamente prescindible, que también podría dejar de existir; de que no existe un "sentido" preordenado, llámese éste "Dios" o "historia", ni un cielo de las ideas con "valores" enclavados, de los cuales uno podría "echar mano", como bien suele decirse. ${ }^{27}$

De hecho, la pérdida de la posición central del hombre en el cosmos fue un proceso que ya se había iniciado a comienzos de la Era Moderna, y que Nietzsche apenas planteó a la conciencia general. En sus "Conferencias de Introducción al Psicoanálisis", Freud describió los tres grandes agravios que el orgullo del hombre había sufrido en el transcurso de la Era Moderna: con Copémico perdió su hogar, aquel punto metafísicamente privilegiado, en torno al cual giraba todo el universo; Darwin le hizo perder su filiación divina para incorporarlo a la ciega evolución de las especies; y a través de Freud, finalmente, tuvo que reconocer que su vanidoso Yo no era ni siquiera amo y señor en su propia casa. ${ }^{28}$

"Sabemos que la destrucción de una ilusión no lleva necesariamente a la verdad, sino que acaso sólo nos ofrece un poco más de ignorancia, una ampliación de nuestro 'espacio vacío', una extensión de nuestro desierto interior". ${ }^{29}$

${ }^{27}$ R. Burger, "Zentralperspektive. Rückblick auf aine optische Täuschung", en Merkur. Deutsche Zeitschrift für europäisches Denken. Stuttgart, 1993, p. 284.

${ }^{28} \mathrm{Cf}$. S. Freud, Vorlesungen zur Einführung in die Psychoanalyse, t. I. Francfort, 1969, p. 283.

${ }^{29}$ F. Nietzsche, op. cit., t. III, p. 446. 
Para poder estar nuevamente en armonía con el mundo, el hombre tuvo que atravesar un periodo intermedio marcado por la falta de sentido, antes de que pudiera emanciparse completamente de las pretensiones cristianas de búsqueda de sentido. Nietzsche expone la lógica inmanente al nihilismo en una parte de su legado de los años ochentas titulada La caída de los valores cosmológicos:

El nihilismo como estado psicológico tendrá que manifestarse; en primera instancia, cuando hayamos buscado un "sentido" en todo lo que acontece, el cual no consiste en que el buscador se desanime. En tal caso, el nihilismo consiste en adquirir conciencia del derroche de energía, de la tortura de la futilidad de las cosas, de la inseguridad, de la falta de oportunidades para recuperarse y tranquilizarse, de la vergüenza ante sí mismo por haberse engañado durante tanto tiempo [...] En resumen, pues, la desilusión ante una supuesta finalidad del devenir como causa del nihilismo, ya sea en relación con un objetivo específico o, en general, el reconocimien. to de la insuficiencia de todas las hipótesis teleológicas hasta ahora encontradas con respecto a la evolución en su totalidad.

En segunda instancia, el nihilismo se manifiesta como estado psicológico si suponemos una integridad, una sistematización in. trínseca y una organización en todo lo que acontece y como trasfondo de todo lo acontecido [...] En el fondo, el hombre ha perdido la fe en su propio valor cuando a través de su existencia no obra un Todo infinitamente valioso; es decir, que sólo concibió ese Todo para poder creer en su propio valor.

El nihilismo como estado psicológico además se manifiesta en una tercera y última forma. Si de los dos puntos anteriores se desprende que el devenir no persigue ningún fin y que en el fondo de todo el devenir impera una gran unidad, en la cual el individuo puede sumergirse como en un elemento extremadamente valioso, sólo queda como el recurso de condenar todo el mundo del devenir como una gran falacia e inventar, como único verdadero, un mun do que se encuentre más allá de aquél. Cuando el hombre reconoce que ese mundo está conformado únicamente por sus necesidades psicológicas, y que realmente no tiene ningún derecho a construirlo, se genera la última forma del nihilismo, la cual conlleva la falta de fe en un mundo metafísico, y se prohibe a sí misma la creencia en un mundo metafísico. Asumiendo este punto de vista, el hombre reconoce como única realidad posible la realidad del devenir, prohibiéndose a sí mismo todo recurso subrepticio a mun- 
dos ocultos y falsas deidades - pero no soporta este mundo, aunque ya no lo quiera negar. ${ }^{30}$

Sin embargo, es el nihilismo activo de Nietzsche el cual, una vez consciente de la imposibilidad de rescatar la antigua cosmovisión, propone la destrucción de las viejas ideas para dar paso a una visión del mundo que ya no requiere de las estructuras de sentido antiguamente constituidas.

Según Deleuze,

[...] el nihilismo tiene aquí un segundo significado, más familiar. En este caso ya no designa un acto de voluntad sino una reacción, una reacción contra el mundo sobrenatural y los valores superiores, cuya existencia y validez niega de un modo general. Ya no se trata de una desvalorización de la vida en aras de valores superiores, sino de la desvalorización de esos mismos valores supremos. Una desvalorización que no significa la futilidad de la vida, sino la nulidad de los mismos valores superiores. Y al mismo tiempo anuncia la gran novedad: detrás de la cortina no hay absolutamente nada que ver. ${ }^{31}$

Hasta aquí Gilles Deleuze. De ahora en adelante, siempre que mencionemos el nihilismo, nos referiremos al nihilismo activo de Nietzsche, el cual, percatándose de su principio rector, la voluntad de poder, acaba por desembocar en el nihilismo clásico. En ćl la esencia del nihilismo se manifiesta en forma a la vez destructiva y creativa; respondiendo a una ley intrínseca, la negación es parte de la afirmación.

"Para poder levantar un santuario hay que derruir un santuario: ésa es la ley". ${ }^{32}$ Según Nietzsche, quien pretende ser un creador en el bien y el mal, debe ser primero un destructor capaz de derruir los valores. "De tal modo, la maldad suprema forma parte de la bondad suprema; pero esta última es la fuerza creadora", 33

El nihilismo activo de Nietzsche no pretende llenar los vacíos originados por la destrucción de las estructuras tradicionales de sentido, sino aprender a vivir con ellos, es decir, aceptar el hecho de que la historia ha producido demasiadas estructuras de sentido, las cuales, a su vez, han generado necesidades que jamás podrían satisfacerse. La esencia del nihilismo activo, o per-

\footnotetext{
${ }^{30}$ Ibid., pp. 676-677.

${ }^{31}$ G. Deleuze, Nietzsche und die Philosophie. Munich, 1976, p. 161.

${ }^{32}$ F. Nietzsche, op. cit., t. II, p. 835.

${ }^{33}$ Ibid., p. 372.
} 
fecto, reside en saber manejar estos vacíos en forma productiva. A esto se refiere Nietzsche en su legado, cuando dice que "el fenómeno normal del nihilismo puede ser un sintoma tanto de fuerza creciente como de creciente debilidad", y que "la fuerza para crear y desear ha aumentado al grado de que ya no necesita valerse ni de interpretaciones generales ni de nuevas formulaciones de sentido". ${ }^{34}$

Gianni Vattimo, uno de los representantes más conocidos de la posmodernidad en Italia, interpretó en ese sentido las expresiones de Nietzsche en su ensayo Apología del nihilismo:

El nihilista perfecto es aquél que ha reconocido el nihilismo como su (única) oportunidad. Lo que actualmente sucede respecto al nihilismo es lo siguiente: estamos comenzando a convertirnos (o estamos logrando convertimos) en nihilistas perfectos. ${ }^{35}$

Precisamente al reconocer la perspectiva de su cosmovisión y comprender la historia como un proceso en el cual nada se realiza, el hombre ya no tiene que llegar a causas últimas y el imperativo de la verdad pierde su razón de ser. Y Vattimo continúa: "Ahí, en ese énfasis puesto en la superfluidad de los valores últimos radica la esencia del nihilismo perfecto" ${ }^{36}$

Pese a que ciertamente constituye una experiencia básica decisiva de nuestro tiempo, la aceptación del nihilismo como punto de partida del pensamiento filosófico personal ha quedado limitada a círculos poco numerosos. Entre éstos figuran, desde luego, los filósofos e intelectuales más consistentes de la posmodemidad, tales como Lyotard, Derrida, Vattimo, Deleuze y también Foucault, si bien éste último sólo parcialmente puede considerarse como perteneciente a esta corriente. No faltaron las impugnaciones por parte de todos los círculos de filósofos cristianos y tradicionales, donde si bien se abrigan dudas respecto de las propias estrategias de reevangelización, se evita a toda costa que éstas trasciendan al público en general. Al mismo tiempo, sin embargo, van en aumento las voces de aquéllos que interpretan la pérdida misma como liberación y ampliación del horizonte, "aun cuando más allá de éste no se aprecie más que la noche vacía de sentido". ${ }^{37}$.

En Alemania, donde -como dice Nietzsche- la mayoría de los filósofos llevan sangre de teólogos en las venas, por lo que son, como en ninguna otra parte, propensos a la metafísica, sólo pocos se han mantenido al margen del gremio con una postura consecuentemente nihilista. El decano de esta co-

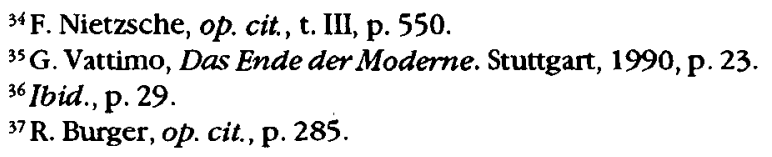


rriente -que por cierto nunca ha llegado a hacer escuela- es indudablemente Hans Blumenberg, cuya obra en su conjunto ilustra la aserción nietzscheana de que "desde Copémico, el hombre rueda del centro hacia la X", ${ }^{38}$ a la que convierte en el tema central de sus investigaciones.

No obstante, a diferencia de Nietzsche, Blumenberg interpreta los procesos en forma sistemática, al reconstruir históricamente el fenómeno que posibilitó el surgimiento del nihilismo. Los mejores documentos de que disponemos para comprender la génesis del nihilismo en el horizonte europeo son precisamente dos de sus tratados, La legitimidad de la Era Moderna y la génesis del mundo copernicano, los cuales nos proporcionan una nueva interpretación tanto de la modernidad como del surgimiento de la cosmología copernicana y de su significado para la autocomprensión de la Era Moderna. En el centro de su interpretación de la Era Moderna se sitúa la mancuerna conceptual de "absolutismo teológico y autoafirmación humana", donde el absolutismo teológico equivaldría a la interpretación nominalista de Dios propia de la Edad Media tardía, mientras que la autoafirmación humana caracterizaría de manera novedosa toda la Era Moderna. Con su insistencia en la soberanía absoluta de Dios, su poder ilimitado y su voluntad soberana, el absolutismo teológico de la escuela nominalista niega al hombre todo discernimiento en relación con la racionalidad de la Creación.$^{39} \mathrm{El}$ mundo -que, desde un punto de vista racional, se ha vuelto incalculable e imprevisiblese manifiesta de una manera radicalmente "contingente", es decir, como "aquella manifestación de la omnipotencia objetivizada, como demostración de la soberanía ilimitada de una voluntad inescrutable". ${ }^{40}$

Sin embargo, si el cosmos está a la merced de la actuación de un dios arbitrario y omnipotente, el orden de ese mundo ya no resulta comprensible. Esto a su vez induce a dudar de la suposición de que el mundo fuera creado expresamente para el hombre, y que éste sea la culminación y el centro de la creación. Antes bien se suscita la idea de que "el creador haya concebido su creación con el único propósito de demostrar su propio poder". ${ }^{41}$

Después de haber elevado a Dios a la cima del poder, comienza a declinar la fe en su confiabilidad. Esta pérdida de confiabilidad de Dios a su vez conduce al menoscabo del orden en el mundo y a un deterioro de la importancia del hombre en el mundo. Es imposible confiar en un dios, que ha privado al hombre de todas sus seguridades metafisicas. En la medida en que aumenta el carácter calculable pero también oculto de Dios, éste va perdiendo su importancia para el hombre, y se convierte en un dios muerto. Por

${ }^{38}$ F. Nietzsche, op. cit., t. III, p. 882.

${ }^{39}$ H. Blumenberg, Die Legitimität der Neuzeit. Francfort, 1988, p. 164.

${ }^{40}$ Ibid., p. 194.

${ }^{41}$ Idem. 
ello, Blumenberg escribe: "El dios nominalista es un dios oculto -y, desde un punto de vista pragmático, un dios oculto equivale a un dios muerto". ${ }^{\text {.2 }}$

En cuanto a la sistemática del pensamiento, esto marca el fin de la Edad Media y el comienzo de la Era Moderna como una época de autoafirmación humana. El hombre, desprovisto de sus garantías de orden y trascendencia desde fines de la Edad Media, se ve cada vez más en la necesidad de autoafirmarse ante un mundo despiadado. ${ }^{43}$

El hecho de perder su posición dentro de la estructura de orden tradicional obliga al hombre a distanciarse de la metafísica y a volver la mirada hacia sí mismo, para elaborar estrategias para dominar el mundo.

La Edad Media cristiana se caracterizaba por una visión muy específica del hombre y del mundo. Se creía poseedora de un saber prácticamente indiscutible y natural acerca del mundo y de la historia, la procedencia del hombre y la finalidad de su existencia. No obstante, al perderse, a fines de la Edad Media y en el curso de la Era Moderna, la credibilidad de este saber casi incuestionado, no desaparecieron al mismo tiempo las interrogantes a las que dicho saber incuestionado había dado respuesta. En otras palabras, la crisis de credibilidad que sufrieron las grandes respuestas medievales originó un exceso de preguntas, que podrían describirșe como un sistema de vacíos en busca de nuevos contenidos. Pero aun si en la Era Moderna impera la necesidad de llenar esos vacíos, Blumenberg coincide en este aspecto casi totalmente con la opinión de Nietzsche de que esta era carece de los medios necesarios para encontrar una respuesta adecuada a las interrogantes heredadas de la Edad Media y no logra llenar adecuadamente el marco de los vacíos que le legara el medioevo cristiano. Los equivalentes modemos de los contenidos teológicos medievales son sustitutos deficientes, meros sucedáneos que se aferran a nuestras desmesuradas esperanzas por encontrar un sentido, aparentando su supuesta realización.

Pero mientras que muchos pensadores de la Era Modema, al llegar a este punto de la reflexión, buscan la salida de esta penosa situación retomando y reviviendo los contenidos teológicos del cristianismo, que antes se daban por sentados, Blumenberg se sustrae a esta tentación y sigue su propio camino, que conduce a consecuencias definidamente nihilistas.

En primera instancia, Blumenberg constata que el cristianismo le dio un nuevo sentido a la historia, al convertir al hombre en el centro del mundo y asegurarle que toda la Creación era sostenida por un dios que se interesa por

${ }^{42}$ Ibid., p. 404.

${ }^{43}$ F. J. Wetz, Hans Blumenberg zur Einführung. Hamburgo, 1993, p. 33. 
la suerte y el destino de los seres humanos. Según Blumenberg, esas estructuras de sentido, que el cristianismo incorporó al sistema de interpretación cosmológica, no son aptas para determinar la realidad. No obstante, a lo largo de los siglos, fueron interiorizadas a tal grado que el cristianismo en el momento de su derrumbamiento deja a la humanidad una tan desmesurada cuan exagerada ansiedad por saber y sentido. Sin embargo, esta misma desmesurada ansiedad por encontrar un sentido se deslegitima a sí misma al exigir a la realidad algo que ésta simplemente no puede dar. Por lo tanto, la manera adecuada de enfrentarse a estas pretensiones de sentido no consiste tanto en tratar de realizarlas, sino, por el contrario, en el intento de reducirlas. Se trata simplemente de romper y destruir totalmente esa necesidad de saber y entender que generó el cristianismo. Pero esto sólo es posible si el hombre reduce las expectativas de sentido planteadas al mundo, para volcarse enteramente a su tarea propiamente dicha, es decir, la de instalarse en el mundo.

Si bien el análisis que Blumenberg hace de la Edad Media cristiana coincide ampliamente con el de Nietzsche, las divergencias entre ambos se ponen de manifiesto en el momento en que Blumenberg analiza la Era Moderna como una época de autoafirmación humana. En su opinión, la Era Moderna no es una deformación distorsionada de la esencia teológica del medioevo cristiano, sino una época que crea sus propias premisas a partir de sí misma y supera así la teoría platónico-cristiana de los dos mundos. Además concibe la Era Modema como respuesta indicada ante el desafío del absolutismo teológico que plantea el nominalismo del medioevo tardio, al alcanzar el hombre moderno su autoafirmación en la civilización técnico-científica.

En La legitimidad de la Era Moderna, Blumenberg describe la ciencia natural moderna ante todo como una instancia que ayuda al hombre a dominar y controlar la naturaleza despiadada y excesivamente poderosa. Por esta razón, la ciencia modema representa uno de los recursos de la autoafirmación del hombre frente a esa naturaleza. En La génesis del mundo copernicano, en cambio, Blumenberg muestra la otra cara del desarrollo científico moderno: no sólo es un medio para domesticar la poderosa naturaleza, sino que al mismo tiempo evidencia en forma aplastante que tal domesticación no es posible.

La ciencia moderna prácticamente nos privó de la ilusión de que nos toque una posición privilegiada y central en la realidad natural del mundo y que esta realidad constituya un sistema de orden abarcable y definido por valores, en el cual se respeten nuestros intereses de supervivencia y de búsqueda de sentido. ${ }^{44}$

${ }^{44}$ Ibid., p. 60. 
Si existe, pues, un factor central que marca La génesis del mundo copernicano, éste consiste precisamente en el descubrimiento de una naturaleza despiadada y arrolladoramente poderosa, promovido por las revelaciones de la ciencia moderna. La denegación de la posición central del hombre en la Tierra va acompañada de un proceso a lo largo del cual éste aprende a concebir el universo sin sentido y sin Dios. Interpretado desde un punto de vista científico, el mundo ya no responde a la interrogante por el sentido último del universo y del hombre, y éste se ve forzado a plantearse esa pregunta sólo a sí mismo. De este modo, sin habérselo propuesto, el objetivismo copernicano produjo una cosmovisión, en la cual el universo perdía su sentido y el hombre su apoyo y valor. En un universo de tales características no podemos dejar de pensar que el hombre es, en realidad, un ser nulo e insig. nificante. En este contexto, Blumenberg se pregunta "¿qué posición ocupaba el hombre en el cosmos en aquella nueva época?", a los que responde lacónicamente: "El hombre no es el destinatario del acontecer cósmico". ${ }^{45}$

A lo largo del ensayo consecuentemente nihilista de Blumenberg, el propio Nietzsche no se salva de la crítica de aquél, pero no por haber fundado el nihilismo, sino por no haberlo llevado hasta sus últimas consecuencias. El reproche de Blumenberg se refiere a que tampoco Nietzsche supo soportar hasta las últimas conclusiones las injurias y humillaciones de la ciencia moderna: si bien reconoce que, conforme vamos adquiriendo más conocimientos, el universo pierde cada vez su sentido y el hombre su importancia, no obstante se muestra incapaz de simplemente "aceptar este hecho como tal". 46

Bien por el contrario, formula una filosofía del eterno retorno y de la voluntad de poder, para así superar la pérdida de sentido del hombre y del mundo, es decir, superar el hecho inapelable de un nihilismo definitivo. Blumenberg considera que, en la actualidad, tales intentos de superar el nihilismo han quedado condenados definitivamente al fracaso.

La certeza de la indiferencia del universo frente al hombre resulta difícil de soportar para el orgullo humano, y Blumenberg no titubea en pensar que, aun si lo supiéramos todo, difícilmente nos abstendríamos de preguntar con un dejo amargo, si eso efectivamente era todo. El hecho de vivir en un planeta minúsculo en medio de un sistema solar que, a su vez, pertenece a una galaxia con un diámetro de cien mil años luz y con cien mil millones de estrellas, nutre las ideas de la insignificancia del hombre. Toda la creación de una milenaria cultura espiritual queda condenada a desaparecer sin rastro, dejando atrás solamente un campo de radiación en constante expansión.

${ }^{45}$ H. Blumenberg, Die Genesis der kopernikanischen Welt. Francfort, 1981, p. 665.

${ }^{46}$ Ibid., p. 129) 
Asi, Blumenberg considera que el conocimiento científico destruye la importancia y singularidad del hombre y lo remite a sí mismo como última instancia. Cuanto más se evidencia que el mundo silencioso e inconmensurable no se preocupa en lo más mínimo por el hombre, tanto más debe el hombre interesarse y preocuparse por sí mismo. De este modo, su mirada se aparta del cosmos y se vuelve hacia su Tierra natal, donde debe aprender a afirmarse ante un entorno que percibe como poderoso y hostil. En ese retorno al mundo, Blumenberg vuelve a coincidir con Nietzsche, quien había concebido la Tierra como el verdadero campo de acción del hombre.

En La legitimidad de la Era Moderna, la ciencia moderna aparece como un medio de autoafirmación humana ante una naturaleza despiadada. En La génesis del mundo copernicano, la naturaleza científicamente estudiada pasa a ocupar el lugar del dios poco confiable de la Edad Media tardía. En este caso, la autoafirmación humana no se hace valer ya contra la arbitrariedad de un dios absoluto, sino contra una naturaleza absoluta y despiadada.

Pero por más que la Tierra carezca de sentido y de razón, no deja de ser digna de consideración en medio de un desierto celeste inanimado, ya que permite el desarrollo de la vida humana, aunque no haya sido creada para tal fin. De esa manera la ciencia le devuelve a la Tierra la posición privilegiada, que antes la hacía estrella entre las estrellas. Presumiblemente la Tierra es el único lugar del universo que posibilita y fomenta una vida consciente, y esto debería constituir un consuelo suficiente para el hombre de la era nihilista. Y con la Tierra como única opción, el hombre debería estar en condiciones de aceptar el adagio de Heinrich Heine que dice: "El cielo, en cambio, se lo cedemos a los ángeles y a los gorriones". 